\title{
TEMPORAL AND SPATIAL VARIABILITY OF TOTAL OZONE IN SOUTHWEST SWEDEN REVEALED BY TWO GROUND-BASED INSTRUMENTS
}

\author{
DELIANG CHEN* and MANUEL NUNEZ \\ Department of Earth Sciences, University of Göteborg, Sweden \\ Received 30 May 1997 \\ Revised 25 November 1997 \\ Accepted 12 January 1998
}

\begin{abstract}
This study deals with temporal and spatial variability of ozone in Southwest Sweden as measured by two ground-based instruments. Daily total ozone values measured by a Brewer ozone spectrophotometer at Norrköping, Sweden are analysed for the period 1988-1997. The analysis not only gives an estimate of the long term annual and seasonal trends, but also provides statistics of means and variability on various temporal scales. The highest decreasing trend was found in spring, while the smallest seasonal trend was in summer. On an annual basis, the long term trend is determined as $-2.61 \mathrm{DU}(0.79 \%)$ per year. The mean annual range of seasonal averages is as high as $96 \mathrm{DU}(29.2 \%)$ with the maximum in October and the minimum in April. On average, variability in summer is much less than in winter whilst spring and autumn experience moderate variations. Large variations from day to day are found to be frequent. A spectral analysis on the daily values shows that the dominating oscillating periods are between 2.1 and 4.5 days, indicating the importance of the synoptic scale influences. Furthermore, the analysis reveals a trend of decreasing variability with decreasing ozone.

To study the spatial variability, measurement from another similar instrument that is located in Oslo is compared to that in Norrköping. Daily values during 1994-1996 are compared, which shows a correlation coefficient of 0.90 . However, the difference between the stations can still be considerable. The standard deviation of the difference is 21.8 DU and the maximum absolute difference is as high as $77.5 \mathrm{DU}$. This certainly has implications for the regional variability of surface UV. (C) 1998 Royal Meteorological Society.
\end{abstract}

KEY WORDS: southwest Sweden; temporal and spatial variability; Brewer spectrophotometer; total ozone

\section{INTRODUCTION}

Despite its small proportion in terms of the total atmospheric composition, ozone plays an important role in global weather and climate as well as surface ecology. Ozone is an important trace gas which absorbs some of the biologically harmful ultraviolet radiation, therefore preventing them from reaching the earth's surface. An early paper by Molina and Rowland (1974) pointed out the potentially damaging effect that anthropogenic chlorofluorocarbon (CFC) emissions may have on the stratospheric ozone layer. Both satellite and surface data have documented a process of high stratospheric ozone depletion in the Antarctic environment during spring months (Farman et al., 1985; Stolarski et al., 1986). Although this effect cannot be expected to apply in other places to the same extent, more recent studies have indicated that ozone depletion is not confined to Antarctica, but that it has global features (Atkinson et al., 1989; Bojkov et al., 1990; Stolarski et al., 1991, 1992). There is some evidence showing that the decreased ozone levels have caused increases of ultraviolet radiation at the surface (Kerr and McElroy, 1993).

\footnotetext{
* Correspondence to: Department of Earth Sciences, University of Göteborg, 41381 Göteborg, Sweden. E-mail: deliang@gvc.gu. seURL: http://www.gvc.gu.se/ngeo/deliang.htm
}

Contract grant sponsor: Swedish Radiation Protection Institute

CCC 0899-8418/98/111237-10\$17.50

(C) 1998 Royal Meteorological Society 
Analyses of total ozone have focused on trend analysis (Reinsel et al., 1994; Bojkov and Fioletov, 1995) due to the increasing concern about dramatically decreasing stratospheric ozone. However, a full description of the variability of ozone should also include means, seasonal variation and extremes. This information should be more useful in understanding ozone dynamics.

Evidence of global stratospheric ozone loss has been largely based on satellite observations. Over the northern hemisphere middle and high latitudes, data from Dobson stations have been used (Krzyscin, 1994). To measure long term trends in total ozone, an accurate instrument is required. The Brewer type spectrophotometer has proven to be one of the world's most accurate ozone-measuring devices (World Meteorological Organisation (WMO, 1994)). It should be remembered that ground-based instruments give point measurements, while satellite data cover a certain area.

The objectives of this work are twofold:

(i) to provide a detailed climatology of total ozone measured by a ground- based instrument in Southwest Sweden;

(ii) to gain some understanding of the spatial variability of ozone in the region by comparing data from two ground-based instruments. This work is part of a research program to investigate regional variability of ultraviolet radiation in Southwest Sweden.

\section{DATA AND ANALYSIS METHOD}

A map showing the study area is given in Figure 1. Oslo in Norway and Norrköping in Sweden are two stations providing ground-based total ozone measurements. Norrköping is located in the southern part of Sweden $\left(\mathrm{N} 58.58^{\circ}\right.$; E16.15०). The station (WMO station number 2071) is operated by the Swedish Meteorological and Hydrological Institute. The instrument used to measure total ozone is of a Brewer type. Measurements are made at 11:00 h local time (LT) if suitable. A detailed description of the instrument and measuring procedure can be found in Josefsson (1992). The data set used in this study encompassed the period from 5 February 1988 to 4 February 1997. Occasionally, there are missing data (about $1 \%$ of the total data) which need to be dealt with in some fashion for calculation of the climatology. Linear interpolation is used to estimate missing values in order to make the time series complete, which enables a computation of monthly and yearly means and a time series analysis of the daily data.

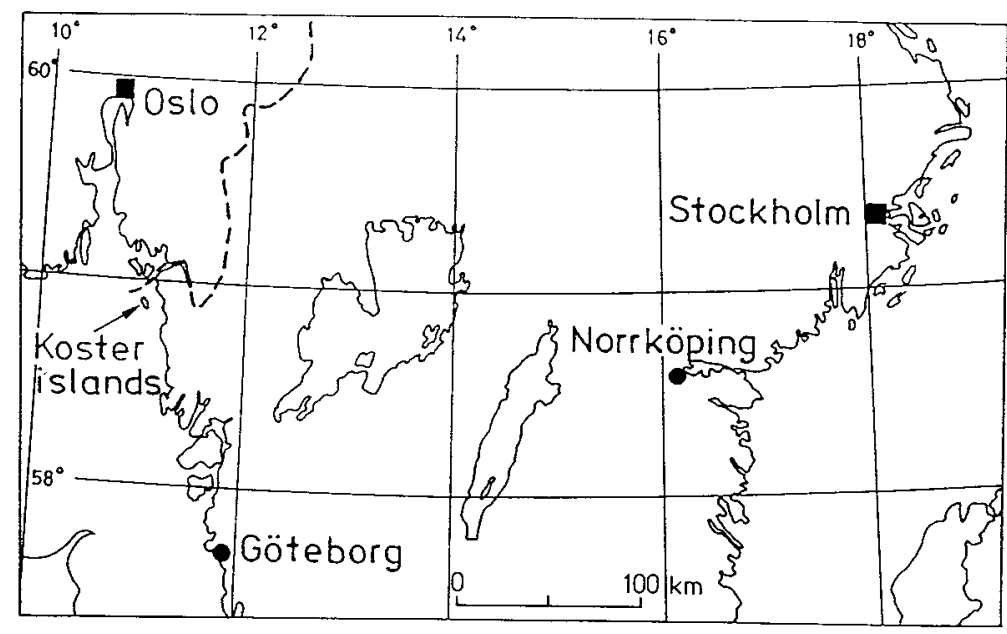

Figure 1. Map of the study region showing the locations of the two stations 
Oslo $\left(59.95^{\circ} \mathrm{N} ; 10.72^{\circ} \mathrm{E}\right)$ is equipped both with a Brewer-type and a Dobson-type instrument. Daily measurements from 1 January 1994 to 31 December 1996 were acquired. For the purpose of comparison with the Norrköping data, the Brewer instrument was used. However, there are some missing values from the Brewer instrument which were replaced by Dobson data if available. This may be considered valid since the difference between the two instruments is small.

All the measurements are obtained at fixed local time, and daily measured values are used directly to analyse day-to-day variability. Monthly and yearly means are calculated based on these daily values, assuming that they are representative of daily means. To study long term trends, a linear regression analysis is used on daily, monthly and yearly means of the total ozone, respectively. The variability is studied by using the standard deviation (S.D.) and the coefficient of relative variation (CRV). CRV is a useful measure for comparing relative variability of two or more variates whose means are dissimilar. It is defined by $\mathrm{CRV}=100 * \mathrm{~S}$.D./M where $\mathrm{M}$ is the arithmetic mean. Power spectral analysis is applied to identify the frequency dependence of the variability, while an autocorrelation function (ACF) is computed to quantify the persistence.

Daily surface air pressure measurements at 12:00 h (LT) from Oslo during 1994-1995 are used to identify weather conditions.

\section{ANALYSIS OF RESULTS}

\subsection{Daily variation}

Figure 2a displays the daily total ozone at Norrköping from 5 February 1988 to February 41997. Despite considerable short term variations, a seasonal change can be seen for the whole period. The mean (M) for the whole period is $330 \mathrm{DU}$ and the standard deviation is $48 \mathrm{DU}$, giving a CRV of $14.6 \%$. The maximum during the period is $521 \mathrm{DU}$ and the minimum $213 \mathrm{DU}$, giving a range of $308 \mathrm{DU}$ which is $93.3 \%$ of the mean value. To see if a long term trend can be identified based on the daily data, a linear regression is applied to the daily values, resulting in a decreasing trend of $-0.00966 \mathrm{DU}$ day ${ }^{-1}$ or -3.53 DU year ${ }^{-1}\left(-1.07 \%\right.$ year $\left.^{-1}\right)$.

The day-to-day variation is clearly seen in Figure 2(b) which displays the intersequential change of the time series in Figure 1(a). The maximum increase in the day-to-day total ozone is $160 \mathrm{DU}(48.5 \%)$ and the maximum decrease $126 \mathrm{DU}(38.2 \%)$. The standard deviation of the intersequential change is $26 \mathrm{DU}$ $(7.9 \%)$, which gives a measure of the mean change from day to day.

To characterise the frequency dependence of the daily change, a spectrum analysis of the daily time series is performed. A 'Box-Cox' transformation is first applied to the time series to ensure the stability of the variance. Then the transformed series is detrended by using a first order differencing. Finally, the frequency dependent variance of the transformed and detrended variable is computed. Figure 3 displays the power of the variance against frequency. There appears to be a strong high frequency component of the variance, which is characterised by a broad band peak between 2.1 and 4.6 day periods. This indicates that the daily ozone variation is strongly influenced by changes occurring at the synoptic scale (Barnston, 1996), which implies that the prediction of total ozone is likely to be limited by the predictability of the weather. It is well known that frequent fast-moving synoptic weather disturbances are often found in the study area. Several investigators have demonstrated that day-to-day variation of ozone is well correlated to daily meteorological conditions (Meetham, 1937; Reed, 1950; Barsby and Diab, 1995).

The dominating short-term variations of ozone points to a short memory of the systems controlling ozone. System memory is sometimes termed persistence, which is an important parameter used in prediction. To characterise the persistence of the system, ACF is calculated with a time lag of up to 100 days. Figure 4 displays the autocorrelation function against time lag. A fast decrease of the correlation within the first few days is observed. With a lag of four days, the correlation function is as low as 0.66. This underlines the importance of the short term variations on the time scale of a few days. It can also be seen that the decrease in ACF begins to slow down after a few days and a stabilisation of ACF is 

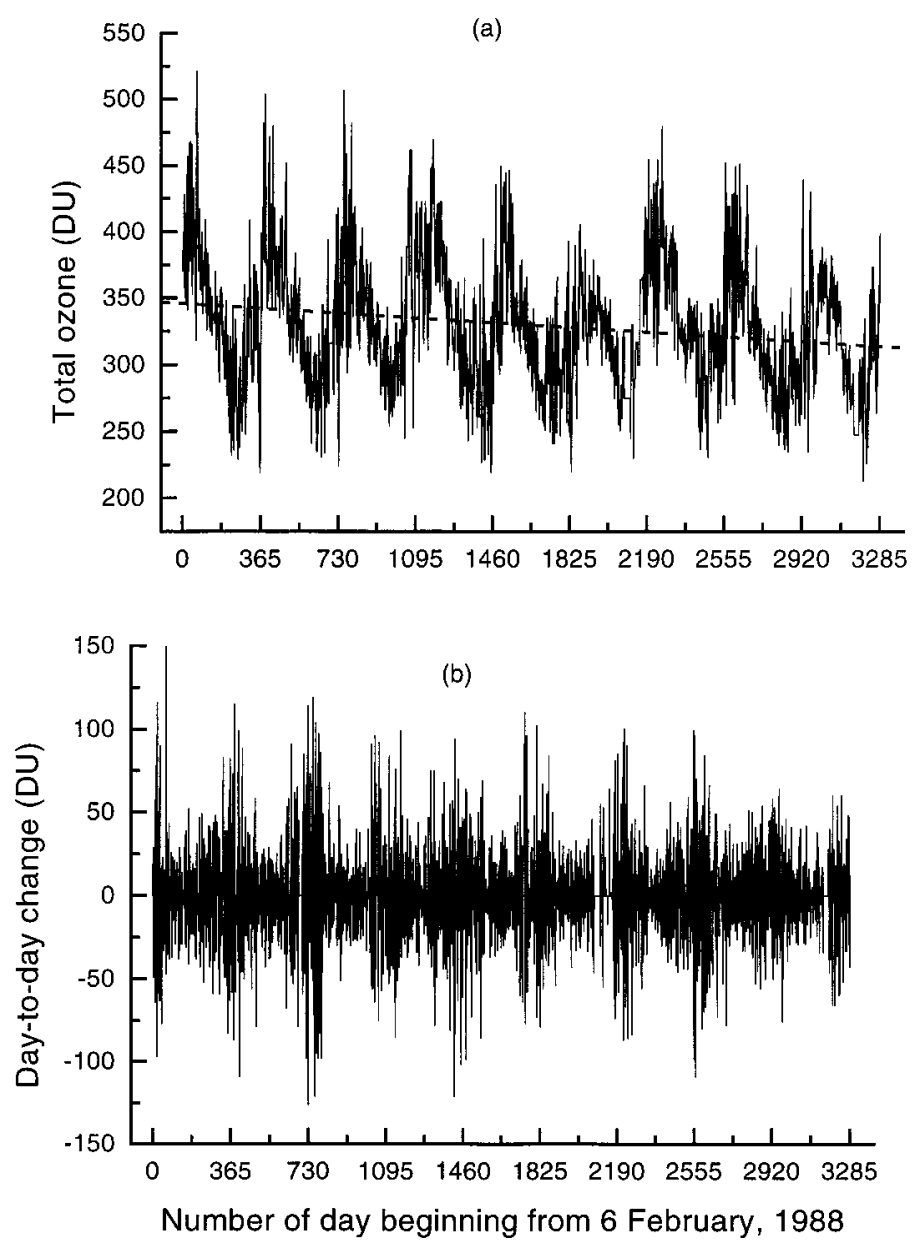

Figure 2. Daily total ozone concentrations in Norrköping (a) and its day-to-day variations (b)

evident from about 5-36 days. The stabilised level of ACF is about 0.5 , indicating the importance of the monthly time scale in terms of persistence. After 37 days, the ACF decreases almost linearly. If 'decorrelation' is defined as $r<1 / e$, then the corresponding time lag can be determined as 49 days. This reveals that a characteristic persistence of the system is of the order of about six weeks. At the lag of 100 days, the ACF is nearly zero.

Temporal variability is usually connected to spatial variability. The fast decrease of the ACF on the short time scale in Norrköping implies that daily total ozone in Oslo may not be the same as that in Norrköping. To quantify the difference, available daily values during 1994-1996 from the two stations are compared. For this purpose, missing values in Norrköping are neglected and no interpolated values are used. Figure 5 gives the difference for all valid data during the three year period. Both positive and negative values are found, with the largest positive one being 75 DU and the largest negative one -77.5 DU. As a result, the average of difference is rather small, only - 3.6 DU. A better parameter to describe the mean difference in this case is the standard deviation (SD) which is estimated to be $21.8 \mathrm{DU}$. A linear regression between the ozone at the two stations gives a correlation coefficient of $0.90(N=1000)$, which indicates that $81 \%$ of the variations in one station can be accounted for by the variations in another one. Although the correlation is fairly high, there is still $19 \%$ of the variation that is 'local' to one of the two stations. It is this local variation that results in differences in the ozone at the two stations.

The differences identified are probably due to transport mechanisms as the two stations are located at about the same latitude. Weather can play an active role in this regard. To see how much synoptic systems 


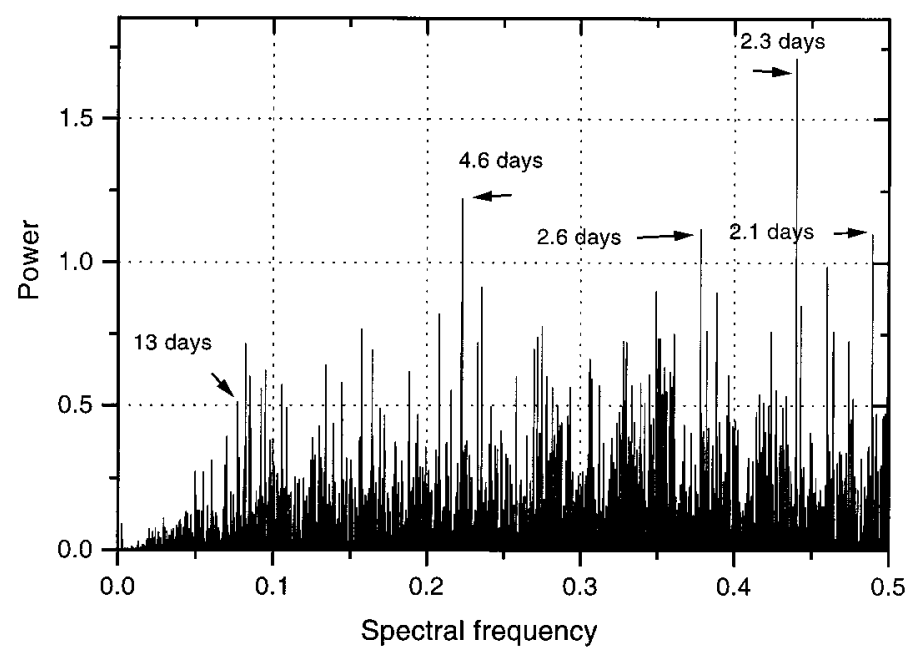

Figure 3. Frequency dependence of daily ozone variations in Norrköping

may affect total ozone, a linear regression analysis is done between the surface pressure in Oslo and the total ozone in Oslo and Norrköping. The correlation coefficients are low, $-0.08(N=1000)$ for Oslo and $-0.11(N=1000)$ for Norrköping. The correlation between the difference of ozone in Norrköping and Oslo and the pressure is even lower, -0.05 . These results are not surprising because the tropospheric ozone is only a small part of the total ozone and the surface pressure is more associated with the tropospheric processes. This points to the need for a comprehensive study including weather variables in the stratosphere to reveal the relationship between the weather and the total ozone (McCormack and Hood, 1994).

\subsection{Monthly variation}

The seasonal variation differs from year to year for the total period. Figure 6(a) displays monthly means from March 1988 to January 1997. The decreasing trend is more obvious than in the daily values.

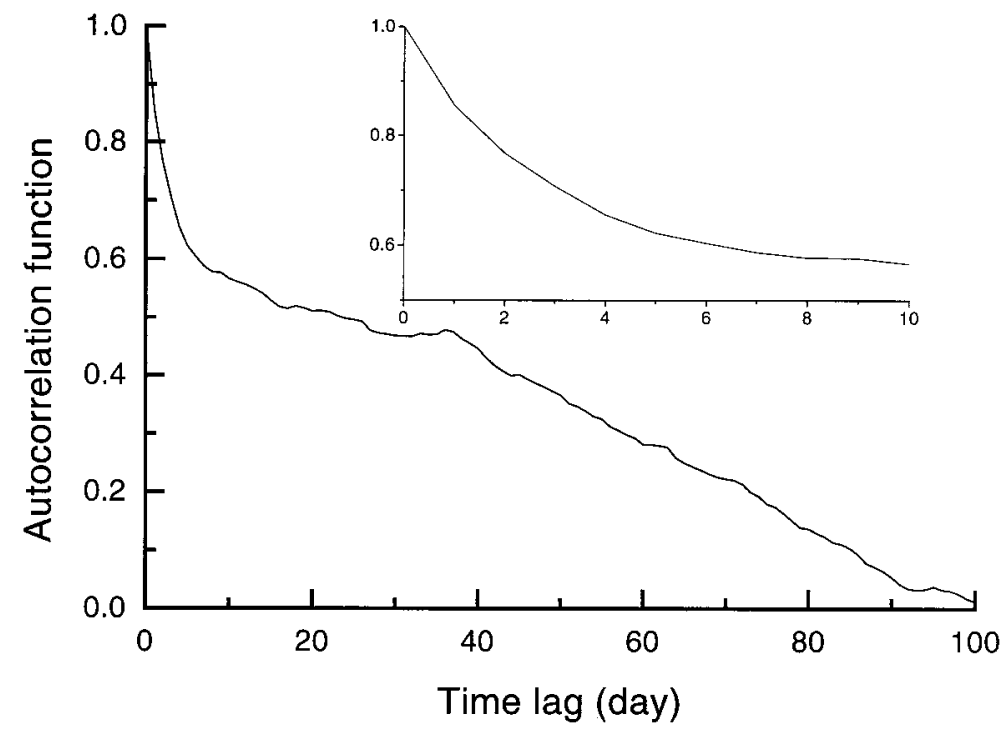

Figure 4. Persistence of daily variations of ozone in Norrköping as measured by lagged autocorrelations 


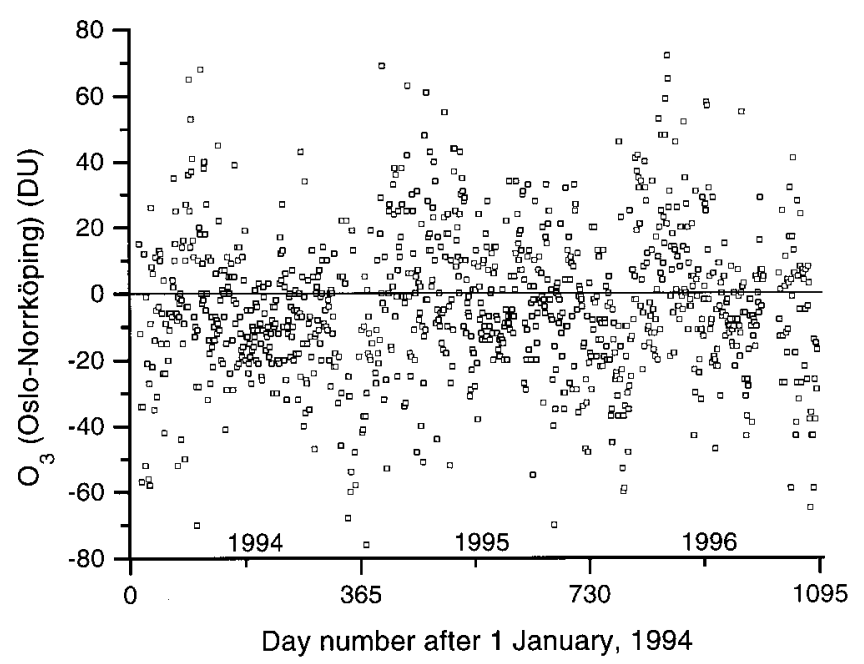

Figure 5. Differences of daily total ozone between Oslo and Norrköping during a three year period

October 1996 showed the lowest record for the whole period. A linear regression of the monthly values gives an estimate of the trend as $-0.280 \mathrm{DU}$ month $^{-1}$ or $-3.36 \mathrm{DU}$ year ${ }^{-1}$. The amplitude of the seasonal cycle tends to decrease with time. During spring 1993, a few months after the Mt. Pinatubo volcanic eruption in the Philippines in June 1991, the ozone level was extremely low. However, it did not last long. By spring 1994 the ozone level had recovered to its normal value.

To identify seasonal changes of day-to-day variability of total ozone, monthly standard deviations based on the daily values for all months are calculated and the results are shown in Figure 6(b). There is a considerable variation among the months. A clear seasonality is also present. The greatest variability is found in winter and the smallest in summer. During 1993-1994 the variability is relatively low, which is most likely due to the Mt. Pinatubo volcanic eruption. Since the monthly means are different, it is desirable to normalise the standard deviations by their corresponding means. By using this measure, CRV, the variability for different months can be readily compared. Figure 6(c) shows the change in this measure. As the standard deviations are relatively small compared to the means, Figure 6(c) shows a similar pattern as Figure 6(b) does. There is a suggestion of decreasing trends in the lowest values, but fairly constant high values, giving rise to a decreased variability with time. It is interesting to note that the decreased variability for the short term and the long term all seem to be linked to low levels of total ozone. The month-to month variation is shown in Figure 6(d). Besides a clear seasonality, short term disturbances are also visible.

To further quantify the seasonal variation, monthly means of the total ozone from 1989 to 1996 are calculated and shown in Figure 7a. The seasonal variation reveals a nearly perfect sine wave with the maximum value of 376 DU in April and the minimum of 280 DU in October. The range of the seasonal change amounts to $96 \mathrm{DU}$ which is $29.2 \%$ of the mean value of 229 DU. Seasonal variation of ozone may be decomposed into two parts, a photochemical and a dynamic part (Aesawy et al., 1994). Since both the production and destruction of ozone depend on solar radiation, the photochemical component is a function of solar intensity. Ozone is produced mainly in the tropics and exported to higher latitudes by the atmospheric circulation which plays an important role for local ozone at higher latitudes. As the maximum and the minimum occur in April-October when solar radiation is about the same, the atmospheric transport must have played a more active role in forming the seasonal pattern. Figure $7 \mathrm{~b}$ gives the means of the monthly SDs and Figure 7c shows the related CRVs.

According to existing analysis, most ozone depletion occurs in the spring at high latitudes. It is thus of interest to estimate the seasonal dependence of the trend associated with the data set used here. A trend is estimated for each of the 12 months during 1989-1996. Then the monthly trends are averaged over a three month period encompassing each season. Table I gives the results for spring (March, April and 
May), summer (June, July and August), autumn (September, October and November), and winter (December, January and February).

It is interesting to note that all months show a decreasing trend although the magnitudes vary. Relatively high trends are found in winter and spring with the maximum in March. This is consistent with other findings (Bojkov et al., 1990).

\subsection{Annual means and trend}

Annual means during the period 1989-1996 are calculated based on the obtained monthly means. The results are shown in Figure 8a. By applying a linear regression to the data, the trend is estimated to be -2.61 DU year ${ }^{-1}$ or $-0.793 \%$ year ${ }^{-1}$. The trend means that on average $6.3 \%$ of the total ozone was lost during the eight year period. The annual trend is exactly the same as the mean of the seasonal trends. This trend might be compared with the global decreasing trend of $5 \%$ and $6.5 \%$ on average for middle and high latitudes in the northern hemisphere during the last 15 years (Bojkov, 1995). However, caution is needed as the short-term trend revealed in this study may change with time (Krzyscin, 1994).

Similarly, annual mean standard deviations and coefficients of relative variations based on the monthly data are calculated and plotted in Figure 8(b) and (c). The variability reflects the day-to-day and month-to-month variations. It is interesting to note that the variability as determined by the two parameters shows a decreasing trend over the whole period. A linear fit gives an estimate of the trend as -0.962 DU year ${ }^{-1}$ or $-0.21 \%$ year $^{-1}$
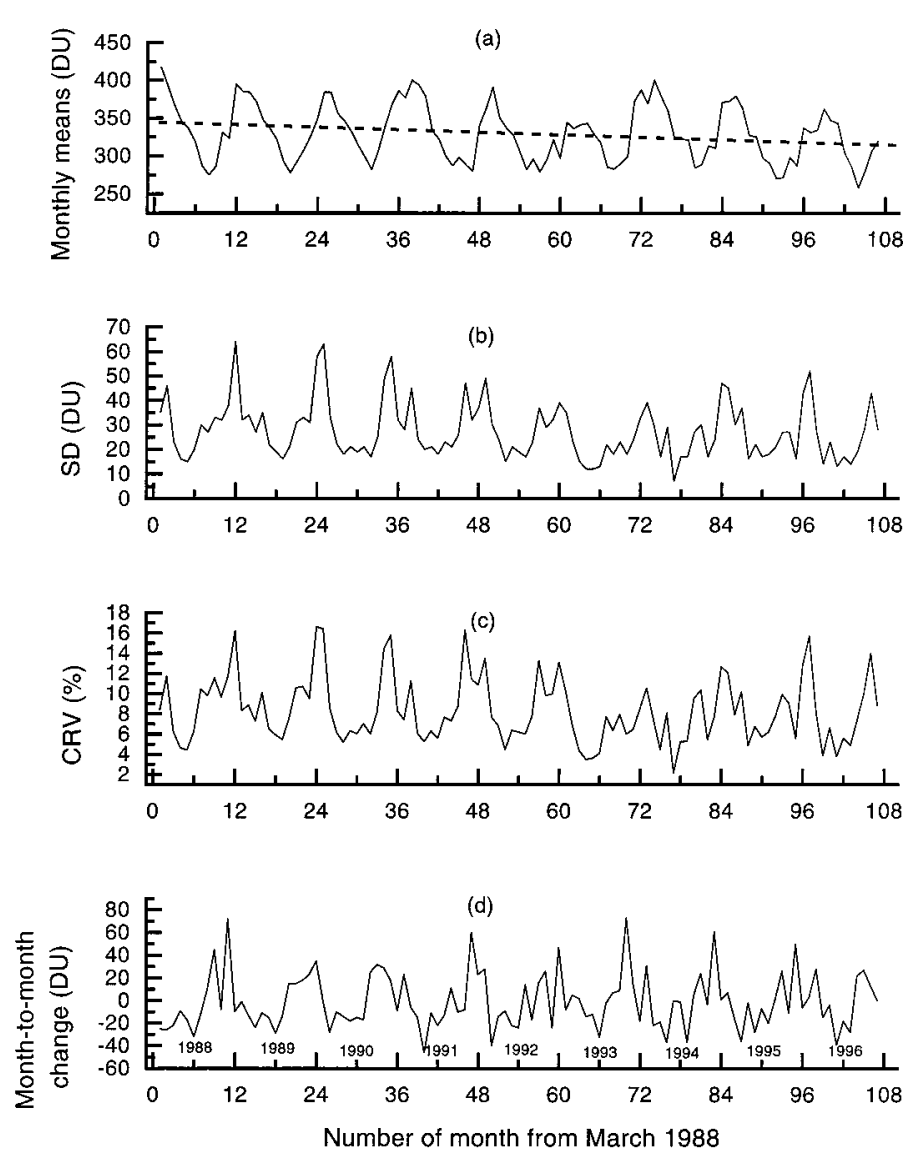

Figure 6. Monthly statistics of the total ozone in Norrköping: (a) monthly means (b) monthly standard deviation (c) monthly coefficient of relative variation (d) month-to-month variation 

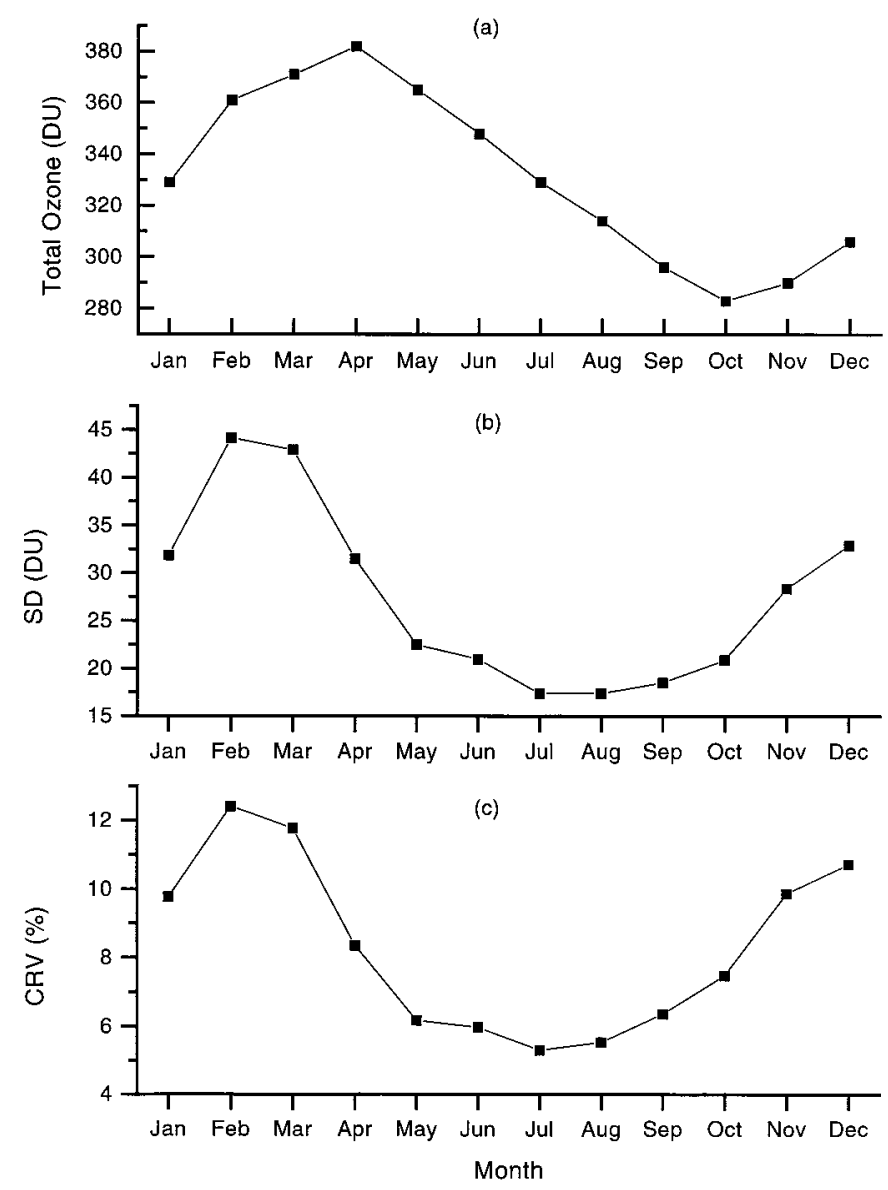

Figure 7. Seasonal variation of total ozone in Norrköping: (a) seasonal means (b) seasonal standard deviation (c) seasonal coefficient of relative variation

\section{SUMMARY AND CONCLUSIONS}

The main purpose of this study was to gain some understanding of total ozone variability in Southwest Sweden in the context of surface UV by examining two ground-based instruments. A detailed climatology of ozone for the last nine years in Norrköping is provided to describe some general features of the ozone variability in the region. In addition, daily ozone from Oslo during a three year period is compared to that in Norrköping to study the spatial variability. The results of the study may be summarised as follows:

(i) A clear downward trend is present in the data set based on daily, monthly and yearly data. During 1989-1996 the annual trend is estimated to be $-2.61 \mathrm{DU}$ year ${ }^{-1}$ or $-0.793 \%$ year $^{-1}$. The seasonal trends range from $-1.43 \mathrm{DU}_{\text {year }}{ }^{-1}$ to $-3.96 \mathrm{DU}$ year ${ }^{-1}$ with the maximum in spring.

(ii) There is a clear seasonal variation $(29.2 \%)$ with a maximum in April and a minimum in October, which to a large extent is related to atmospheric transport processes.

Table I. Seasonal trends

\begin{tabular}{llllll}
\hline Season & Spring & Summer & Autumn & Winter & Mean \\
\hline DU year $^{-1}$ & -3.96 & -1.43 & -2.08 & -2.97 & -2.61 \\
$\%$ year $^{-1}$ & -1.20 & -0.44 & -0.63 & -0.90 & -0.79 \\
\hline
\end{tabular}



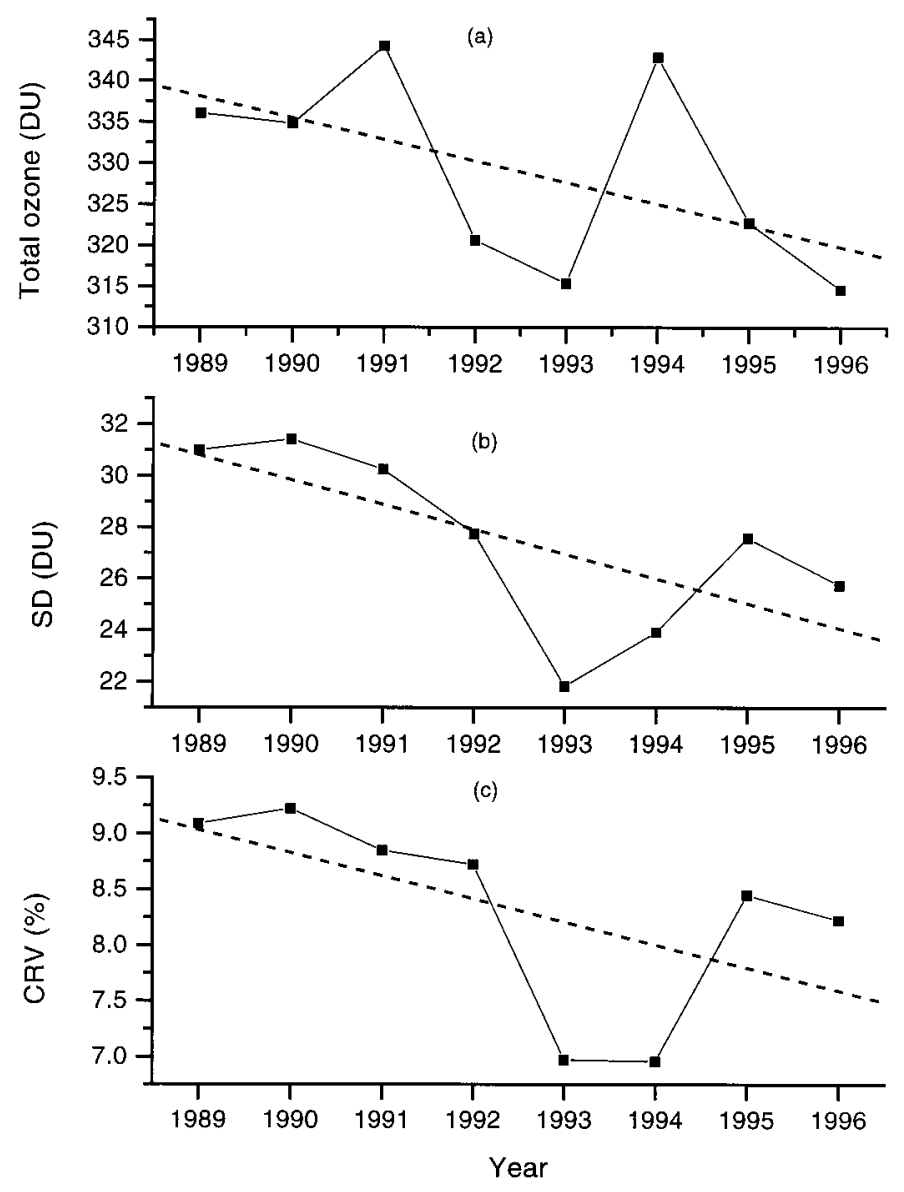

Figure 8. Yearly statistics of total ozone in Norrköping: (a) annual means (b) annual standard deviation (c) annual coefficient of relative variation. Dotted lines are fitted linear trends

(iii) On a daily basis, periodic oscillation of 2.1-4.5 days dominates the variation. This points to the importance of changes at the synoptic scale, which has implications for forecasting of the daily total ozone. Further research is desirable to clarify possible links between the weather and total ozone. On a monthly basis, the variability is greatest in winter and least in summer, while that for spring and autumn lie in between. This again indicates the important role played by atmospheric transport.

(iv) The day-to-day variation is greatest and it ranges from a maximum decrease of $126 \mathrm{DU}$ to a maximum increase of $160 \mathrm{DU}$. The month-to-month variation is moderate and shows a maximum increase of 73 DU and a decrease of 46 DU, respectively. The year-to-year change is the smallest with a maximum increase and decrease of only 28 DU and 23 DU, respectively.

(v) There has occured a decreasing variability of total ozone over a nine year period.

(vi) The difference between the total ozone in Oslo and Norrköping can be considerable, though the correlation between the two is as high as 0.90 . On a daily basis, the maximum absolute difference can be as large as 77.5 DU (23.5\%). The standard deviation of the difference is $21.8 \mathrm{DU}(6.6 \%)$. This implies that ozone can be an important factor in producing differences in surface UV on that spatial scale. 


\section{ACKNOWLEDGEMENTS}

The authors of this paper would like to thank Finn Tonnessen and Weine Josefsson for kindly providing ozone data for Oslo and Norrköping, respectively. Solveig Svensson is acknowledged for drawing the map. This research is funded by Swedish Radiation Protection Institute.

\section{REFERENCES}

Aesawy, A.M., Mayhoub, A.B. and Sharobim, W.M. 1994. 'Seasonal variation of photochemical and dynamical components of ozone in subtropical regions', Theor. Appl. Climatol., 49, 241-247.

Atkinson, R.J., Matthew, W.A., Newman, P.A. and Plumb, R.A. 1989. 'Evidence of the midlatitude impact of Antarctic ozone depletion', Nature, 340, 290.

Barnston, A.G. 1996. 'Time-scales of the variability of the atmosphere', Int. J. Clim, 16, 499-535.

Barsby, J. and Diab, R.D. 1995. 'Total ozone and synoptic weather relationships over southern Africa and surrounding oceans', J. Geophys. Res., 100, 3023-3032.

Bojkov, R., Bishop, L., Hill, W.J., Reinsel, G.C. and Tiao, G.C. 1990. 'A statistical trend analysis of revised Dobson total ozone data over the northern hemisphere', J. Geophys. Res., 95, 9785-9807.

Bojkov, R.D. 1995. The changing ozone layer, WMO and UNEP, pp. 25.

Bojkov, R.D. and V.F. Fioletov, 1995. 'Estimating the global ozone charateristics during the last 30 years', J. Geophys. Res., 100, 16537-16551.

Farman, J.C., Gardiner, B.G. and Shanklin, M.R. 1985. 'Large losses of total ozone in Antarctica reveal seasonal CIOX /NOX interaction', Nature, 315, 207-210.

Josefsson, W. 1992. Measurements of total ozone, PMK report, Swedish Environmental Protection Agency, pp. 64.

Kerr, J.B. and McElroy, C.T. 1993. 'Evidence for large upward trends of ultravioletB radiation linked to ozone depletion', Science, 262, $1032-1034$.

Krzyscin, J.W. 1994. 'Changes in ozone trends over the northern hemisphere middle latitudes during the period 1970-1990', Theor. Appl. Climatol, 49, 1-7.

McCormack, J.P. and Hood, L.L. 1994. 'Relationship between ozone and temperature trends in the lower stratosphere-Latitude and seasonal dependence', Geophys. Res. Lett., 21, 1615-1618.

Meetham, A.R. 1937. 'The correlation of the amount of ozone with other characteristic of the atmosphere', Quart. J. Roy. Meteor. Soc., 63, 289-307.

Molina, M.J.and Rowland, F.S., 1974. 'Stratospheric link for chloro-fluoro-methanes: chlorine atom catalysed destruction of ozone', Nature, 249, 810-814.

Reinsel, G.C., Tiao, G.C., Wuebbles, D.J., Kerr, J.B. Miller, A. J., Nagatani, R. M., Bishop, L. and Ying, L. H. 1994. 'Seasonal trend analysis of published groundbased and TOMS total ozone data through 1991', J. Geophys. Res., 99, 5449-5464.

Reed, R.J. 1950. 'The role of vertical motions in ozone-weather relationships', J. Meteorol., 7, 263-267.

Stolarski, R.S., Krueger, A.J., Schoeberl, M.R., McPeters, R.D., Newman, P.A. and Alpert, J.C., 1986. 'Nimbus 7 satellite measurements of the springtime Antarctic ozone decrease', Nature, 322, 808-811.

Stolarski, R.S., Bloomfield, P., McPeters, R.D. and Herman, J.R. 1991. 'Total ozone trends deduced from Nimbus 7 TOMS data', Geophys. Res. Lett., 18, 1015.

Stolarski, R.S., Bojkov, R., Bishop, L., Zerefos, C., Stachelm, J. and Zaaurodny, J. 1992. 'Measured trends in stratospheric ozone', Science, 256, 342-349.

WMO, 1994. Scientific assesment of ozone depletion, World Meteorological Organisation Report No. 37, Geneva. 